\title{
Multikonferenz Wirtschaftsinformatik (MKWI)
}

Die Multikonferenz Wirtschaftsinformatik (MKWI) findet vom 26. bis 28.02.2014 in Paderborn statt.

Sie ist seit mehr als einem Jahrzehnt der traditionelle Treffpunkt der deutschsprachigen Wirtschaftsinformatik in den geradzahligen Jahren. Sie richtet sich an Wissenschaftler, Praktiker und Studierende, die an aktuellen Entwicklungen von Informations- und Kommunikationstechnologien und ihren Anwendungen in einem ökonomischen Umfeld interessiert sind.

Im Jahr 2014 findet die MKWI in Paderborn statt, wo die Wirtschaftsinformatik eine lange Tradition hat. Bereits Anfang der 70er-Jahre wurden an dieser „Universität der Informationsgesellschaft" die ersten Wirtschaftsinformatiklehrstühle eingerichtet und der Studiengang Wirtschaftsinformatik feiert im Jahr 2014 seinen 25-jährigen Geburtstag.

Veranstaltungsort ist das Heinz Nixdorf MuseumsForum (HNF) in Paderborn. Dieses zeigt seit seiner Eröffnung am
24. Oktober 1996 die Geschichte der Informationstechnik von der Keilschrift bis zu neuesten Entwicklungen der Robotik und Künstlichen Intelligenz. In neuen Erlebniswelten können Themen wie Robotik und Künstliche Intelligenz, Mobile Kommunikation oder Digitalisierung erfahren werden. Die Ausstellungsbereiche präsentieren aktuelle Themen der Informationstechnik interaktiv und multimedial. Besucher können alte und neue Computerspiele testen, Mensch-MaschineSchnittstellen ausprobieren oder im Showroom neueste Anwendungen und Produkte aus Forschung und Industrie erproben. Eine multimediale Inszenierung präsentiert $150 \mathrm{Pi}$ oniere der Computergeschichte.

Mehr über die Höhe der Teilnahmegebühren, die Inhalte der angebotenen Workshops, Tutorien und Keynotes erfahren Sie unter: www.mkwi2014.de Hier können Sie sich außerdem direkt für die Teilnahme an der Konferenz registrieren.

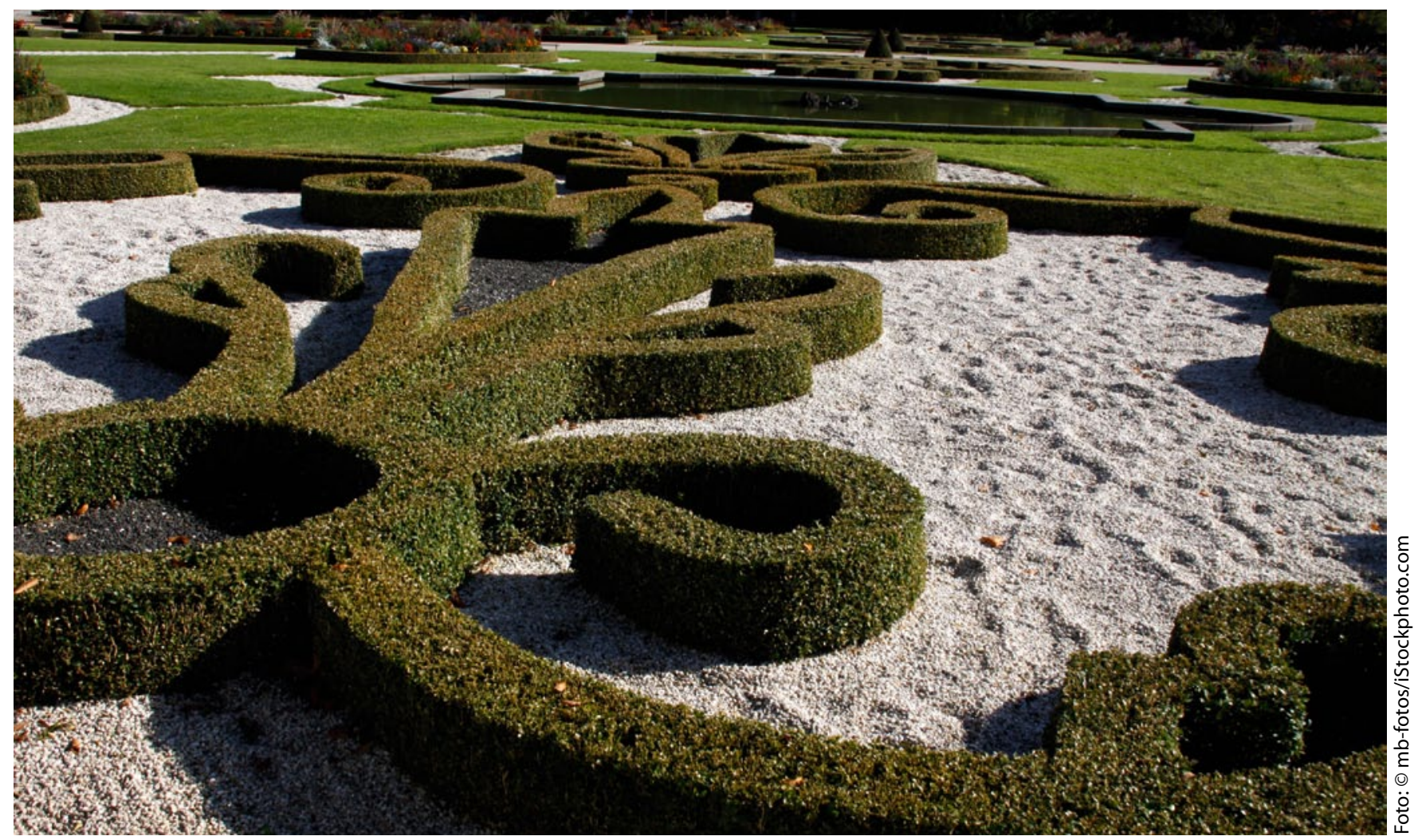

Barockgarten von Schloss Neuhaus, Paderborn 